\title{
Continuous Epidural Hydromorphone Infusion for Post-Cesarean Delivery Analgesia in a Patient on Methadone Maintenance Therapy: A Case Report
} This article was published in the following Dove Press journal:
Journal of Pain Research

\author{
Mellany A Stanislaus (D) \\ Joseph L Reno' \\ Robert H Small ${ }^{\prime}$ \\ Julie H Coffman ${ }^{2}$ \\ Mona Prasad ${ }^{3}$ \\ Avery M Meyer (D) $^{4}$ \\ Kristen M Carpenter ${ }^{4}$ \\ John C Coffman (1D)
}

'Department of Anesthesiology, The Ohio State University Wexner Medical Center, Columbus, OH, USA;

${ }^{2}$ Department of Internal Medicine, Riverside Methodist Hospital, Columbus, OH, USA; ${ }^{3}$ Department of OBGYN, Riverside Methodist Hospital, Columbus, OH, USA; ${ }^{4}$ Department of Psychiatry, The Ohio State University Wexner Medical Center, Columbus, OH, USA
Correspondence: John C Coffman Department of Anesthesiology, The Ohio State University Wexner Medical Center, Room N-4I I North Doan Hall, 410 West I0th Avenue, Columbus, OH 43210, USA Tel $+1|6| 42938487$

Fax +116142938153

Email john.coffman@osumc.edu

\begin{abstract}
The prevalence of opioid use disorder (OUD) in the United States has more than quadrupled over the past two decades. This patient population presents a number of challenges to clinicians, including difficult pain management after surgical procedures due to the development of opioid tolerance. Significantly greater opioid consumption and pain scores after cesarean delivery have been reported in patients with OUD compared to other obstetric patients. A multi-modal analgesic regimen is generally recommended, but there are few wellestablished pain management strategies after cesarean delivery specific to patients with OUD. We present the case of a patient with OUD maintained on daily methadone that received a continuous epidural hydromorphone infusion for post-cesarean analgesia, a technique not previously reported in obstetric patients and only rarely described for patients undergoing other surgical procedures. The patient received epidural anesthesia for cesarean delivery, and after surgery, the epidural catheter was left in place for the epidural hydromorphone infusion, initiated at $140 \mathrm{mcg} / \mathrm{hr}$ and continued for approximately $40 \mathrm{hrs}$. This strategy reduced her average daily oral opioid consumption by $97 \%$, reduced self-reported pain scores, shortened the length of hospitalization and improved ability to ambulate compared to her previous cesarean delivery. The use of continuous epidural hydromorphone infusion was effective in this case, and this analgesic technique may also be applicable to other types of surgical procedures with the potential for significant post-operative pain, particularly in patients with OUD.
\end{abstract}

Keywords: continuous epidural hydromorphone, opioid use disorder, cesarean delivery, medication-assisted treatment, methadone

\section{Introduction}

Keeping pace with the opioid epidemic in the United States, the prevalence of opioid use disorder (OUD) has more than quadrupled among obstetric patients over the past 20 years. ${ }^{1}$ Opioid abuse or dependence in pregnancy increases the risk for a number of adverse maternal and fetal outcomes, including maternal death, cardiac arrest, placental abruption, preterm labor, intrauterine growth restriction, stillbirth and neonatal abstinence syndrome. ${ }^{2,3}$ In addition to these risks, a particularly challenging aspect in patients with OUD is effectively managing their pain after cesarean delivery. Previous retrospective studies have demonstrated approximately a $50-70 \%$ increase in daily opioid requirements and increased pain scores after cesarean delivery in patients on either methadone or buprenorphine maintenance therapy compared to control patients. ${ }^{4,5}$ Despite the increasing prevalence of OUD 
in obstetric patients and evidence for greater pain and opioid requirements after cesarean delivery, there are only a few published reports and small case series to guide pain management strategies for these patients. Previous authors have described intravenous (IV) patientcontrolled analgesia (PCA), IV ketamine and dexmedetomidine infusions, and continuous epidural local anesthetic infusions with and without clonidine for post-cesarean delivery analgesia. ${ }^{6-11}$ Regional truncal blocks (transversus abdominis plane, quadratus lumborum and ilioinguinal-iliohypogastric blocks) or surgeon wound infiltration have also been suggested as a potentially beneficial part of multi-modal post-cesarean delivery analgesia, though no studies have been specifically performed in OUD patients undergoing cesarean delivery. ${ }^{11,12}$ We present the novel technique of using continuous epidural hydromorphone infusion for post-cesarean analgesia in a patient with OUD maintained on daily methadone, and compare her daily opioid use, self-reported pain scores, and length of hospitalization to her first cesarean delivery in order to highlight the potential analgesic benefits of post-operative epidural hydromorphone infusion compared to standard management.

\section{Consent}

Written informed patient consent was obtained to publish the details of this case. Other than written patient consent, there is no additional institutional approval required to publish the case details.

\section{Case Report First Delivery}

A 27-year-old G1P0 patient at 35 weeks 6 days gestation presented for cesarean delivery of a dichorionic diamniotic twin pregnancy complicated by chronic hypertension with superimposed preeclampsia. Her other significant past medical history included opioid use disorder and morbid obesity (body mass index (BMI) $47.5 \mathrm{~kg} / \mathrm{m}^{2}$ ). Upon initiation of prenatal care, she was maintained on methadone $85 \mathrm{mg}$ daily and reported use for 1 year through an opioid treatment program. The methadone dose was incrementally increased throughout the pregnancy to $105 \mathrm{mg}$ daily and ultimately $165 \mathrm{mg}$ daily through delivery. There were no reported adverse drug interactions and electrocardiogram (ECG) monitoring did not reveal QT prolongation. A combined spinal-epidural (CSE) block procedure was performed at L4/5. Spinal medications included $0.5 \%$ bupivacaine $1.8 \mathrm{~mL}$, morphine $200 \mathrm{mcg}$, fentanyl 10mcg, and epinephrine $200 \mathrm{mcg}$. The epidural was dosed incrementally with $2 \%$ lidocaine with 1:200,000 epinephrine $13 \mathrm{~mL}$ to maintain patient comfort during the surgical procedure. The operative course was uncomplicated.

The epidural catheter was left in place after surgery and a continuous epidural infusion of $0.0625 \%$ bupivacaine with fentanyl $4 \mathrm{mcg} / \mathrm{mL}$ was initiated at $10 \mathrm{~mL} / \mathrm{hr}$ (patientcontrolled dose $4 \mathrm{~mL}, 15$-mins lockout) and continued until approximately $18 \mathrm{hrs}$ post-operatively. The patient reported generally effective pain relief during this time, though she was not able to ambulate due to partial motor block from the epidural local anesthetic infusion. Her other postoperative management included scheduled oral methadone $165 \mathrm{mg}$ daily, IV ketorolac (given from 0 to $24 \mathrm{hrs}$ ), oral ibuprofen (given from $24 \mathrm{hrs}$ until discharge). Oral oxycodone and oral acetaminophen were available as needed for breakthrough pain. Pain control was difficult after epidural catheter removal, reflected by average daily oral oxycodone $85 \mathrm{mg}$ per $24 \mathrm{hrs}$ (range $45-100 \mathrm{mg}$ per $24 \mathrm{hrs}$ ) and average maximum daily pain scores of 8/10 (range 7-10/10) during her hospitalization after delivery. No significant events were observed on continuous pulse oximetry and telemetry monitoring during her hospitalization. Hospital discharge occurred 3 days 22 hrs after delivery (Table 1).

\section{Second Delivery}

Approximately 2.5 years after her first delivery, the patient was then a 30-year-old G2P0102 that presented for repeat cesarean delivery at 38 weeks, 2 days gestation. Her past medical history was similar, though she was now maintained on methadone $190 \mathrm{mg}$ daily and her BMI was $39.4 \mathrm{~kg} / \mathrm{m}^{2}$ at the time of delivery. At the time prenatal care was initiated, she was maintained on methadone $160 \mathrm{mg}$ daily before being increased by an opioid treatment program to methadone $190 \mathrm{mg}$ daily before the time of delivery. No adverse drug interactions or QT prolongation on ECG were documented. For this cesarean delivery, an epidural was placed at the L3/4 level and incrementally dosed with $0.5 \%$ ropivacaine $25 \mathrm{~mL}$, morphine $2 \mathrm{mg}$ and fentanyl $85 \mathrm{mcg}$. The intraoperative course was uncomplicated.

About 30 mins after delivery, continuous epidural hydromorphone infusion was initiated at $140 \mathrm{mcg} / \mathrm{hr}$ (patient-controlled dose $20 \mathrm{mcg}$, 30-mins lockout). Over $24 \mathrm{hrs}$, she would receive epidural hydromorphone $3.36 \mathrm{mg}$ from the infusion. No patient-delivered boluses were administered. Her other postoperative analgesic regimen was similar to that of her first delivery, including 
Table I Patient Characteristics, Anesthetic Details and Analgesic Outcomes After Cesarean Deliveries

\begin{tabular}{|c|c|c|}
\hline & Cesarean Delivery \#I & Cesarean Delivery \#2 \\
\hline Age (years) & 27 & 30 \\
\hline Gravidity & 1 & 2 \\
\hline Parity & 0 & 2 \\
\hline Gestational age (weeks, days) & $35 w 6 d$ & $38 w 2 d$ \\
\hline Birth weight (grams) & $\begin{array}{l}1869(\operatorname{twin} A) \\
\text { I } 720(\text { twin } B)\end{array}$ & 2910 \\
\hline Apgar scores (I min, 5 mins) & $\begin{array}{l}8,9(\operatorname{twin} A) \\
9,9(\operatorname{twin} B)\end{array}$ & 8,9 \\
\hline $\begin{array}{l}\text { Delivery-to-discharge (hrs) } \\
\text { Methadone dose at delivery (mo/day) }\end{array}$ & $\begin{array}{l}94 \\
165\end{array}$ & $\begin{array}{l}52 \\
190\end{array}$ \\
\hline \multicolumn{3}{|l|}{ Anesthetic Details } \\
\hline $\begin{array}{l}\text { Combined spinal-epidural } \\
\text { Spinal bupivacaine }(\mathrm{mg}) \\
\text { Spinal fentanyl }(\mathrm{mcg}) \\
\text { Spinal morphine }(\mathrm{mcg}) \\
\text { Spinal epinephrine }(\mathrm{mcg})\end{array}$ & $\begin{array}{l}9 \\
10 \\
200 \\
200\end{array}$ & $\begin{array}{l}- \\
- \\
- \\
-\end{array}$ \\
\hline $\begin{array}{l}\text { Epidural } \\
\text { Epidural local anesthetic }(\mathrm{mL}) \\
\text { Epidural fentanyl }(\mathrm{mcg}) \\
\text { Epidural morphine }(\mathrm{mg})\end{array}$ & $\begin{array}{l}13 \\
\text { (2\% lidocaine with I:200,000 epinephrine) } \\
- \\
-\end{array}$ & $\begin{array}{l}25 \\
(0.5 \% \text { ropivacaine }) \\
85 \\
2\end{array}$ \\
\hline \multicolumn{3}{|l|}{$\begin{array}{l}\text { Postpartum Pain Scores and Analgesic } \\
\text { Medications }\end{array}$} \\
\hline Average daily maximum pain score $(0-10)$ & 8 & 5 \\
\hline Average daily oral oxycodone (mg per $24 \mathrm{hrs}$ ) & 85 & 2.5 \\
\hline Post-operative epidural infusion & $\begin{array}{l}0.0625 \% \text { bupivacaine with fentanyl } 4 \mathrm{mcg} / \\
\mathrm{mL}-10 \mathrm{~mL} / \mathrm{hr} \times 18 \mathrm{hrs} \\
\text { (patient-controlled dose } 4 \mathrm{~mL} \\
\text { 15-mins lockout) }\end{array}$ & $\begin{array}{l}\text { Epidural Hydromorphone - } 140 \mathrm{mcg} / \mathrm{hr} \times 40 \\
\text { hrs } \\
\text { (patient-controlled dose - hydromorphone } \\
20 \mathrm{mcg}, 30 \text {-mins lockout) }\end{array}$ \\
\hline $\begin{array}{l}\text { IV ketorolac (mg per } 24 \mathrm{hrs} \text { - given from 0-24 hrs } \\
\text { postpartum) }\end{array}$ & 90 & 120 \\
\hline $\begin{array}{l}\text { Oral ibuprofen (mg per } 24 \text { hrs - given from } 24 \text { hrs } \\
\text { postpartum until discharge) }\end{array}$ & 3200 & 3200 \\
\hline Oral acetaminophen (mg per $24 \mathrm{hrs}$ ) & 2437.5 & 650 \\
\hline Respiratory rate (breaths/min) & $14-20$ & $14-18$ \\
\hline SPO2 (\%) & $94-100 \%$ & $94-98 \%$ \\
\hline
\end{tabular}

scheduled oral methadone $190 \mathrm{mg}$ daily, IV ketorolac (0$24 \mathrm{hrs}$ ) and oral ibuprofen (from $24 \mathrm{hrs}$ until discharge). Oral oxycodone and oral acetaminophen were available as needed for breakthrough pain. Her overall analgesia was superior compared to the first cesarean delivery, reflected by average daily oral oxycodone $2.5 \mathrm{mg}$ per $24 \mathrm{hrs}$ (range 0-5 mg per $24 \mathrm{hrs}$ ) and average maximum daily pain scores of 5/10. Importantly, she was able to ambulate without difficulty during the epidural hydromorphone infusion, which was continued for approximately $40 \mathrm{hrs}$ and 
stopped $12 \mathrm{hrs}$ prior to hospital discharge. The patient did not experience side effects of nausea or pruritus, and no respiratory depression or somnolence was apparent on clinician assessments or continuous pulse oximetry monitoring (respiratory rate $14-18$ breaths $/ \mathrm{min}, \quad \mathrm{SPO} 2$ 94-98\%). She was discharged 2 days 4 hrs after delivery, and her overall satisfaction was much greater after her second cesarean delivery (Table 1).

\section{Discussion}

Obstetric patients with OUD are commonly managed with opioid agonist pharmacotherapy, as supervised withdrawal has been associated with high relapse rates. ${ }^{13}$ Among recommended medication-assisted treatment options, buprenorphine is commonly utilized for many patients given that they can be treated on an outpatient basis without the need for directly observed therapy and fewer dosage adjustments may be required during pregnancy. ${ }^{13}$ Additionally, buprenorphine has been associated with a lower incidence of preterm birth and less severe neonatal abstinence syndrome compared to methadone. ${ }^{13-15}$ Despite these potential advantages of buprenorphine, pregnant women with OUD, such as the one described in this case, may still be maintained on methadone. Due to physiologic changes during pregnancy, methadone dose adjustments are often needed to prevent withdrawal due to rapid drug metabolism, especially in the third trimester. ${ }^{13}$ Methadone also has the potential for significant drug interactions that increase the risk of complications like respiratory depression. ${ }^{13}$ Despite having anxiety and bipolar depression, the patient, in this case, was not maintained on benzodiazepines or other medications during either pregnancy, and there were no reported adverse drug interactions. Additionally, ECG monitoring through her opioid treatment program did not demonstrate any QT prolongation and no adverse events were observed on continuous telemetry and pulse oximetry monitoring after each delivery.

Regardless of the type of opioid maintenance therapy, the management of post-cesarean delivery pain in women with OUD remains a formidable challenge for obstetric anesthesiologists. For example, Meyer et al reported that 33 women on maintenance methadone therapy had higher post-cesarean delivery pain scores and as much as a $70 \%$ increase in opiate use compared to controls. ${ }^{4}$ Despite a multimodal approach including both non-steroidal anti-inflammatory drugs (NSAIDs) and acetaminophen, the average daily oxycodone reported in this retrospective cohort was $91.6 \mathrm{mg}$ oxycodone per $24 \mathrm{hrs},{ }^{4}$ which is similar to the experience at our institution as well as the first cesarean delivery of the patient in this case report (Table 1). A multimodal analgesic approach emphasizing non-opioid medications is generally recommended for postpartum analgesia. ${ }^{11}$ Other reported strategies for post-cesarean delivery analgesia in patients with OUD include IV PCAs, IV dexmedetomidine or ketamine infusions, regional anesthesia, and continuous epidural local anesthetic infusions with or without clonidine. ${ }^{6-12}$ For her first cesarean delivery, the patient, in this case, did have a continuous lumbar epidural infusion $(0.0625 \%$ bupivacaine, fentanyl $4 \mathrm{mcg} / \mathrm{mL}$ ) continued for 18 -hrs postdelivery. This strategy provided effective pain relief while the epidural was in place, but it limited her ability to ambulate and early mobilization after cesarean delivery is generally recommended. ${ }^{16}$ Prior authors have described epidural placement at T10-11, which enabled that patient to ambulate during the continuous epidural local anesthetic infusion. ${ }^{8}$

A recent retrospective study compared single-dose neuraxial hydromorphone (intrathecal hydromorphone $60 \mathrm{mcg}$ or epidural hydromorphone $0.6 \mathrm{mg}$ ) to morphine (intrathecal morphine $200 \mathrm{mcg}$ or epidural morphine $3 \mathrm{mg}$ ) after cesarean delivery, and reported comparable analgesia and side effect profiles, though morphine may provide more prolonged analgesia. ${ }^{17}$ Although continuous epidural hydromorphone has been used after thoracic, abdominal, pelvic surgeries and post-laminectomy syndrome, ${ }^{18-21}$ no studies or reports specifically examine its efficacy after a cesarean delivery or in patients with OUD. We selected a continuous epidural hydromorphone infusion for the patient's second delivery in order to take advantage of the specific ability of epidural opioids to provide analgesia without significant motor blockade. ${ }^{22}$ Additionally, pharmacologic advantages of epidural hydromorphone include its intermediate lipophilicity, resulting in earlier onset of analgesia compared to morphine (15 vs 30-60 mins) and longer duration of action compared to fentanyl (10-20 vs 2$3 \mathrm{hrs}){ }^{12,22}$ Clinical benefits include its equal or lower potential for delayed respiratory depression and significantly less pruritus compared to morphine. ${ }^{12,18-20,22}$

Prior studies utilizing continuous epidural hydromorphone for postoperative analgesia report infusion rates ranging from $30 \mathrm{mcg} / \mathrm{hr}$ to $300 \mathrm{mcg} / \mathrm{hr}^{18-21}$ Our current institutional standard for continuous hydromorphone epidural infusions utilizes a formulation of hydromorphone $0.1 \mathrm{mg} / \mathrm{mL}$, with common initial infusion rates of 1-1.2 mL/hr (hydromorphone 100-120 $\mathrm{mcg} / \mathrm{hr}$ ), with patient-controlled doses of $0.2 \mathrm{~mL}$ (hydromorphone $20 \mathrm{mcg}$, lockout $30 \mathrm{mins})$. For the patient in this case, we opted to start epidural hydromorphone at a slightly higher 
rate, $140 \mathrm{mcg} / \mathrm{hr}$, because of her history of OUD and expected tolerance. We were able to optimize her pain relief and she was able to ambulate sooner with the basal rate of epidural hydromorphone $140 \mathrm{mcg} / \mathrm{hr}$ alone. Additional studies are warranted to determine optimal dosing regimens that maximize pain relief and minimize the potential for side effects.

Limitations of this technique are the potential for maternal side effects, including pruritus, nausea and respiratory depression. Although not observed in our patient, Ruan et al report anasarca extending to a patient's thorax after continuous lumbar epidural hydromorphone following laminectomy. The rate used in this case was epidural hydromorphone $30 \mathrm{mcg} / \mathrm{hr}$, significantly lower than our patient. Following the cessation of the infusion and diuresis, the edema resolved. ${ }^{21}$ Despite the potential for maternal side effects, none were observed in the patient described in this report. Neonatal side effects of maternal medications should be considered as well. Studies on the effects of hydromorphone on lactation are limited to a case report on maternal use of oral hydromorphone resulting in infant apnea, and transfer of hydromorphone into breast milk after intranasal administration. ${ }^{23,24}$ Low dose morphine is generally the preferred opiate for postoperative pain control as it has the least amount of secretion in breast milk. Due to the increased potency of hydromorphone, the recommendation is to limit its use while breastfeeding. ${ }^{25}$ The neonates, in this case, had normal Apgar scores and none were observed to have excessive somnolence, apnea or other concerning symptoms attributable to hydromorphone exposure. All neonates were monitored in the neonatal intensive care unit after birth given maternal methadone use, and all were treated for neonatal abstinence syndrome for 4-5 days prior to hospital discharge.

\section{Conclusion}

In this case, the use of a continuous epidural hydromorphone infusion optimized pain relief, as evidenced by significantly reduced pain scores, oral opioid consumption and length of hospitalization compared to her previous delivery. Her ability to ambulate was also improved relative to her previous cesarean delivery in which she received lumbar epidural local anesthetic infusion. We propose that utilization of continuous epidural hydromorphone may, therefore, be a viable approach for improving overall postoperative performance after cesarean delivery in women with OUD. This post-operative analgesic technique may also be applicable to other types of surgical procedures with the potential for significant post-operative pain.

\section{Disclosure}

The authors report no conflicts of interest in this work.

\section{References}

1. Haight SC, Ko JY, Tong VT, Bohm MK, Callaghan WM. Opioid use disorder documented at delivery hospitalization - United States, 1999-2014. Morb Mortal Wkly Rep. 2018;67:845-849.

2. Maeda A, Bateman BT, Clancy CR, Creanga AA, Leffert LR. Opioid abuse and dependence during pregnancy: temporal trends and obstetrical outcomes. Anesthesiology. 2014;121:1158-1165. doi:10.1097/ ALN.0000000000000472

3. Patrick SW, Davis MM, Lehmann CU, Cooper WO. Increasing incidence and geographic distribution of neonatal abstinence syndrome: United States 2009 to 2012. J Perinatol. 2015;35:650-655. doi:10.1038/jp.2015.36

4. Meyer M, Wagner K, Benvenuto A, Plante D, Howard D. Intrapartum and postpartum analgesia for women maintained on methadone during pregnancy. Obstet Gynecol. 2007;110(2 Pt 1):261-266. doi:10.1097/01.AOG.0000275288.47258.e0

5. Meyer M, Paranya G, Keefer NA, Howard D. Intrapartum and postpartum analgesia for women maintained on buprenorphine during pregnancy. Eur J Pain. 2010;14:939-943. doi:10.1016/j.ejpain.2010.03.002

6. Jones HE, Johnson RE, Milio L. Post-cesarean pain management of patients maintained on methadone or buprenorphine. Am J Addict. 2006;15:258-259. doi:10.1080/10550490600626721

7. Tith S, Bining G, Bollag L. Management of eight labor and delivery patients dependent on buprenorphine (Subutex ${ }^{\mathrm{TM}}$ ): a retrospective chart review. F1000Res. 2018;7:7. doi:10.12688/f1000research.13350.1

8. Leighton BL, Crock LW. Case series of successful postoperative pain management in buprenorphine maintenance therapy patients. Anesth Analg. 2017;125:1779-1783. doi:10.1213/ANE.0000000000002498

9. Wasiluk IM, Castillo D, Panni JK, Stewart S, Panni MK. Postpartum analgesia with dexmedetomidine in opioid tolerance during pregnancy. J Clin Anesth. 2011;23:593-594. doi:10.1016/j.jclinane. 2010.09.013

10. Hoyt MR, Shah U, Cooley J, Temple M. Use of epidural clonidine for the management of analgesia in the opioid addicted parturient on buprenorphine maintenance therapy: an observational study. Int J Obstet Anesth. 2018;34:67-72. doi:10.1016/j.ijoa.2018.01.001

11. Landau R. Post-cesarean delivery pain. Management of the opioid-dependent patient before, during and after cesarean delivery. Int J Obstet Anesth. 2019;39:105-116. doi:10.1016/j.ijoa.2019.01.011

12. George RB, Carvalho B, Butwick A, et al. Postoperative analgesia. In: Chestnut DH, Wong CA, Tsen LC, editors. Obstetric Anesthesia Principles and Practice, 6th. Philadelphia: Elsevier; 2020:635-650.

13. Committee on Obstetric Practice. Committee opinion no. 711: opioid use and opioid use disorder in pregnancy. Obstet Gynecol. 2017;130: e81-e94. doi:10.1097/AOG.0000000000002235

14. Zedler BK, Mann AL, Kim MM, et al. Buprenorphine compared with methadone to treat pregnant women with opioid use disorder: a systematic review and meta-analysis of safety in the mother, fetus and child. Addiction. 2016;111:2115-2128. doi:10.1111/add.13462

15. Tran TH, Griffin BL, Stone RH, Vest KM, Todd TJ. Methadone, buprenorphine, and naltrexone for the treatment of opioid use disorder in pregnant women. Pharmacotherapy. 2017;37:824-839. doi:10.1002/phar. 1958

16. Macones GA, Caughey AB, Wood SL, et al. Guidelines for postoperative care in cesarean delivery: enhanced recovery after surgery (ERAS) society recommendations (part 3). Am J Obstet Gynecol. 2019;221:247.e1-247.e9. doi:10.1016/j.ajog.2019.04.012

17. Marroquin B, Feng C, Balofsky A, et al. Neuraxial opioids for post-cesarean delivery analgesia: can hydromorphone replace morphine? A retrospective study. Int J Obstet Anesth. 2017;30:16-22. doi:10.1016/j.ijoa.2016.12.008 
18. Brodsky JB, Chaplan SR, Brose WG, Mark JB. Continuous epidural hydromorphone for postthoracotomy pain relief. Ann Thorac Surg. 1990;50:888-893. doi:10.1016/0003-4975(90)91113-P

19. Chaplan SR, Duncan SR, Brodsky JB, Brose WG. Morphine and hydromorphone epidural analgesia. A prospective, randomized comparison. Anesthesiology. 1992;77:1090-1094. doi:10.1097/ 00000542-199212000-00008

20. Liu S, Carpenter RL, Mulroy MF, et al. Intravenous versus epidural administration of hydromorphone. Effects on analgesia and recovery after radical retropubic prostatectomy. Anesthesiology. 1995;82:682-688. doi:10.1097/00000542-199503000-00010

21. Ruan X, Tadia R, Liu H, Couch JP, Lee JK. Edema caused by continuous epidural hydromorphone infusion: a case report and review of the literature. J Opioid Manag. 2008;4:255-259. doi:10.5055/jom.2008.0029
22. Macres SM, Moore PG, Fishman SM, et al. Acute pain management. In: Barash PG, Cullen BF, Stoelting RK, editors. Clinical Anesthesia, 8th ed. Philadelphia: Wolters Kluwer; 2017:1583-1584.

23. Schultz ML, Kostic M, Kharasch S. A case of toxic breast-feeding? Ped Emer Care. 2019;35:e9-e10. doi:10.1097/PEC.0000000000001009

24. Edwards JE, Rudy AC, Wermeling DP, Desai N, McNamara PJ. Hydromorphone transfer in breast milk after intranasal administration. Pharmacotherapy. 2003;23:153-158. doi:10.1592/phco.23.2.153.32081

25. Lamvu G, Feranec J, Blanton E. Perioperative pain management: an update for obstetrician-gynecologists. Am J Obstet Gynecol. 2018;218:193-199. doi:10.1016/j.ajog.2017.06.021

\section{Publish your work in this journal}

The Journal of Pain Research is an international, peer reviewed, open access, online journal that welcomes laboratory and clinical findings in the fields of pain research and the prevention and management of pain. Original research, reviews, symposium reports, hypothesis formation and commentaries are all considered for publication. The manuscript management system is completely online and includes a very quick and fair peer-review system, which is all easy to use. Visit http:// www.dovepress.com/testimonials.php to read real quotes from published authors. 